CERIAS Tech Report 2002-18

Virtual Orality:

How eBay Controls Auctions without an Auctioneer's Voice

by Josh Boyd

Center for Education and Research in

Information Assurance and Security,

Purdue University, West Lafayette, IN 47907 
Running head: VIRTUAL ORALITY

CERIAS Tech Report 2002-18

Virtual Orality:

How eBay Controls Auctions without an Auctioneer's Voice

\author{
Josh Boyd \\ Purdue University \\ Center for Education and Research in Information Assurance and Security (CERIAS) \\ Department of Communication \\ 1366 Beering Hall of Liberal Arts and Education 2114 \\ West Lafayette, IN 47907-1366 \\ 765.494 .3333 \\ boyd@purdue.edu
}

Portions of this work were supported by sponsors of the Center for Education and Research in Information Assurance and Security.

\begin{abstract}
Auctions are communication-intensive enterprises. Most scholarly examinations of auctions, however, have come from economics and sociology. This essay argues that eBay, the largest online auction, has maintained safety, order, and interest in its auctions by mimicking the oral style of the auctioneer and following the linguistic rules of in-person auctions, but in a virtual space.
\end{abstract}




\section{Virtual Orality}

Auctioneer, $n$. The man who proclaims with a hammer that he has picked a pocket with his tongue.

-Ambrose Bierce, The Devil's Dictionary

A lot of people are intimidated by auctions. They fear being recognized for bids they never intended to make, they are confused by the array of items, they are unclear about terms like choice or by the piece, two times the money; ${ }^{\mathrm{i}}$ and they have difficulty making their minds up fast enough to get in on a sale before the bidding stops. They are afraid of getting stuck with an inferior item at a ridiculous price. Ultimately, however, they put their trust in the person in charge: the auctioneer.

The auctioneer controls the sometimes frenzied proceedings orally. Cassady $(1967,165)$ noted that "The auctioneer's appearance, voice, rhythm of patter, good nature, imperturbability, and storytelling ability may have an effect on bidding activity, thus enhancing prices." Often amplified by a microphone, the auctioneer's voice rises above the din of the crowd and the assistants to maintain order and demand the attention of prospective bidders. If, for instance, a person is erroneously recognized for a bid, the auctioneer has the discretion and power to make things right. And, naturally, the auctioneer wants to do so, because auctioneers want people to feel comfortable and safe at auctions. Whatever the situation, the auctioneer's voice organizes and controls the proceedings.

An audible voice is missing, however, from a new kind of auction that has appeared in the past five years. This auction still sells items to the highest bidder, it still can be confusing, and it still is a jumble of items and action and unfamiliar terms, but with one notable absence: 
there is no auctioneer. This auction is the on- line auction, and instead of a single person orally controlling the auction, there is only a website. Instead of a bidder able to observe competing bidders in the crowd, there are only "buyer" and "seller" usernames. And yet these on-line auctions, led by industry behemoth eBay, have thriven. How is this so? Across cultures and times, auctions have taken place under the supervision of an auctioneer whose voice commands attention and maintains order. On-line auctions have to create hypertext messages that somehow compensate for the missing orality. This essay argues that eBay, and other auction websites like it, is actually not that different from live English auctions of livestock, antiques, fish, tobacco, broadcast licenses, household goods, or myriad other items (Cassady 1967). On the contrary, in a virtual space eBay has maintained order and interest by mimicking the auctioneer's oral style and the rules of in-person English auctions.

\section{On-line Auctions and Communication}

Auctions represent one of the most communication-intensive methods of selling-because price is actually determined through the chanting and bidding processes, communication about value is central to the successful completion of any auction. Considering the critical importance of communication to auctions, a method through which most used cars, beef, and tobacco in the U.S. (among other things) pass on their way to consumers, it is remarkable that auctions have been so ignored regarding their linguistic performance. With the exception of Kuiper (1992, 1996), explorations of auctions have come from sociology (Smith 1989) or business and economics (Cassady 1967; DeVany 1987; Kagel and Levin 1993; Hendricks and Paarsch 1995; Lucking-Reiley 2000). Cassady (1967) calls his overview "the beginning, not the end" of understanding auctions. This essay attempts to add a communication perspective to the 
understanding of auctions by focusing on the elements of linguistic performance recreated in online auctions.

On-line auctions are a rapidly growing segment of Internet commerce. Not only did they account for \$1.4 billion in trade in 1998 (Grant 1999), but they have attracted major on-line players such as amazon.com and Yahoo! as well as traditional auction house Sotheby’s. Specialty auctions also exist for just about anything, from CigarBids.com to PatentAuction.com to Pharmabid.com (“Surfing” 1998; “A New” 1999; Rundle 1999). But eBay, as the first and largest person-to-person Internet auction, is the optimal choice for this case study. EBay has grown so rapidly that its third quarter transactions alone in 2000 equaled the $\$ 1.4$ billion in trade accounted for by all Internet auctions for the entire year of 1998 (“EBay Inc. Releases” 2000). As of January 2001, eBay boasted 22.5 million registered users ("EBay Inc. Announces” 2001). A year earlier, eBay CEO Meg Whitman had boasted that eBay's daily dollar volume (with just 7.7 million registered users) was “15 times [its] next-largest competitor” (Anders 1999b, B6). The previous quarter, eBay users were responsible for an astounding $5 \%$ of all person-to-person shipments in the U.S. (Anders 1999a). EBay has also established a site that makes people comfortable enough to stay. Nielson/Netratings reported that in October 2000, among the 25 most visited websites on the Internet, eBay $\left(14^{\text {th }}\right.$, with over 17 million unique visitors in the month) was by far the "stickiest." In fact, the average eBay visitor spent over two hours and ten minutes at the site, compared to just one hour and forty-one minutes at second-place Yahoo! (Nielson//Netratings, 2000). On a typical day, eBay boasts over five million auctions in progress. EBay is without question the biggest and most well-known on-line auction. EBay is not as novel, however, as it might present itself to be. EBay and other on-line 
auctions are certainly global, but auctions have been part of a global economy for a long time. Auctions occurred in China in the seventh century B.C. and in Babylon in the sixth century B.C. (Cassady 1967). Wool auctions in Australia, fish auctions in the Phillippines and Israel, fur auctions in Russia, tea auctions in the U.K., tobacco auctions in the United States (5-6, 269290)-all have long been very much a part of (non-virtual) global commerce. EBay may not own the items sold on its site, but neither do most auctioneers (Smith 1989). Even the timed nature of eBay's auctions, which differs from many auctions where the auction continues as long as two or more bidders remain, is not new. In Great Britain in the late 1600s, timed-interval auctions were very popular. Bids proceeded in ascending order, but with a set end-time, often determined by a sand timer or a pin in a candle (Cassady 1967). And eBay's system of "proxy bidding" has a live-auction counterpart-“book bids," where a person leaves a bid in absentia and allows the auctioneer to bid on his or her behalf up to a maximum price (Cassady 1967, 152). An eBay proxy bid is "a maximum bid which is held in confidence by the system. The eBay system will use only as much of the maximum bid as is necessary to maintain the bidder's high bid position" ("Proxy Bidding” 2000).

In economic terms, eBay, in spite of its lack of an auctioneer, is set up primarily as an English auction. In such an auction (typically conducted orally), "the auctioneer initially solicits a bid at a low price and then gradually increases the price until only one bidder remains active" (Graham and Marshall 1987, 1218). The English (ascending-price) auction system stands in contrast to the Dutch (descending-price) auction, where an auctioneer announces a figure much higher than anyone is expected to bid and then reduces that figure until someone accepts the item(s) for sale at that price (Cassady 1967). Unlike English auctions where several bidders are 
likely to become involved in the bidding, a Dutch auction ends with the first bid.

EBay also takes the appearance of a non-sealed bid auction, because others' bids are open for inspection-users can click on "bid history" to see who the bidders are and in what order they have bid. Unlike a sealed auction, eBay bidders also know what the current bid is at any given moment. In a sealed-bid auction, the highest bid submitted might be significantly above the second-highest. At eBay, it will only be one increment above the second-highest bid, no matter what the high bidder's potential maximum. ${ }^{\text {ii }}$ In practice, however, the inability to see other bidders or know their maximums (which are revealed in a live auction by the "losers tell the truth" axiom described below) is similar in some ways to a sealed-bid auction. Kagel and Levin (1993) noted that experimentally, sealed bid auctions yield higher revenue. Further research on on-line auctions might investigate the question of whether eBay's unusual combination of revelation and concealment in bidding gets higher prices and whether that can be associated with unknown maximums, faceless bidders, and no auctioneer to quickly bring about closure.

Researching this question would pose serious methodological problems, however, due to the vast number of potential bidders at eBay's virtual bazaar. As (primarily) a non-sealed bid, English auction, then, eBay works the same way as wholesale used car auctions, fine art auctions, and local household goods auctions: it provides a (virtual) space for the intersection of supply, demand, and competition (Cassady 1967).

\section{The Auctioneer's Role}

In order to keep bids coming in an English auction, the auctioneer is traditionally the key figure, the star performer (Smith 1989). The auctioneer must fundamentally create a feeling of community in which there is trust and participation, or the auction will fail. This is particularly 
important, Smith noted, when not all bidders are physically present and some bids are left or phoned in. In order to create this level of community within which auctions function, "there is always the need for a skilled auctioneer to direct the production" by establishing the proper amount of social distance. This usually involves decreasing social distance through such techniques as addressing bidders by name, telling jokes and stories, and introducing auction assistants (56). Cassady (1967) has also written about the auctioneer's role in an English auction, focusing on the "chant" by which the auctioneer recognizes and asks for bids. The chant includes a starting price (which might or might not be suggested by the auctioneer), actual bids received, the next bid sought (which indicates the increment between bids), filler words and phrases, and the announcement of sale. "The key functionary in auction sales," wrote Cassady, "is the auctioneer" (92).

The chant itself, though different auctions apply it in different ways, establishes a rhythm for the auction (Smith 1989). Auctions are by nature ambiguous and contingent-the value of items is unknown until a price is determined by the gathered community. A chant introduces an element of consistency and form to this uncertain process. The persistent nature of the auctioneer's chant also rises above the din of bidders and sellers examining items, discussing items, and bidding, so that the auctioneer maintains control of the proceedings. The auctioneer, through the chant, controls the duration of bidding on each item, suggests bid increments, prolongs bidding through filler words and banter so that potential bidders have more time to consider their bids, and sometimes even appeals to specific bidders for help (Smith 1989). The chant, then, functions to personalize an auction and locate order and control in the person of the auctioneer, the steady voice that can be heard above all else. 
Though there is much variation in auctioneer-directed English auctions, depending on location, auction community, and what is being sold, Kuiper (1992) has proposed a theory of proto English Auction Speech, based on his study of various auctions throughout New Zealand, the United Kingdom, and North America. This theory answers the question, what rules are common to all oral English auctions? There are three rules: I will deal with each in turn, discussing first how the rule operates in live auctions and then how it is enacted at eBay.

$$
\begin{aligned}
& \text { Rule 1: auction } \rightarrow \text { description }+ \text { opening bid search }+ \text { bid calling }+ \\
& \text { sale }+ \text { (epilogue) }[\text { Kuiper 1992, 281] }
\end{aligned}
$$

The auctioneer describes each item sold and points out any imperfections or important information about the item. Cassady (1967) noted that part of the auctioneer's job is to promote the items for sale. Because most auctioneers make money on commissions, it is in their best interests to praise items and promote bidding. Though items are typically sold "as is" at auctions, auctioneers are also able and often willing to take back items when bidders find damage or find the item to be different than they expected (Smith 1989). Consequently, the description of the item is key to maintaining fairness and ensuring satisfaction.

On eBay, descriptions are not the responsibility of the auctioneer, but of the seller. Whoever puts an item up for bid is obligated to describe it in as much detail as necessary to give potential bidders an accurate understanding of the item's good and bad qualities. The description on eBay is generally much more involved than at an in-person auction because there is no opportunity for potential bidders to inspect an item at close range. A live auctioneer might say, 
for instance, "We have here a nice yellow Rookwood vase from 1928. It has a small chip inside the mouth." This description is simply to elaborate on what people have seen from their own close inspections. On eBay, however, users have no opportunity for inspection of the item itself, only inspection of a photo of the item. A thorough description would also include specific measurements, an explanation of any detail on the vase, the size and nature of the chip, and any maker's marks located on the underside of the vase. As eBay suggests to sellers, "A short, descriptive title and a complete description of your item will also help your sales. But be truthful in your listings. Disappointed buyers are likely to leave you negative feedback" ("How to Sell" 2000)_or in user parlance, "to neg you."

The self-interest of the seller creates an even greater ethical challenge than it does for the auctioneer, who will receive only a percentage of the selling price. The seller has strong economic reasons to misrepresent items so that they seem more desirable. This is particularly true for occasional sellers on eBay. For more active eBay sellers, however, eBay's feedback system provides a strong deterrent for misrepresentation. After an auction is completed on eBay, buyers have the opportunity to leave feedback for sellers, describing the transaction as "positive," "negative," or "neutral," and leaving up to an 80-word comment. This provides a record of the seller's history and provides strong motivation for sellers to write thorough and accurate descriptions, lest their future auctions be ignored because bidders doubt descriptions. Even if dishonest sellers continue to register under different names, they will never be able to build up a high feedback rating that would engender trust. So strong is this motivation that this author had an experience as high bidder in which, after an auction ended, the seller discovered very minor damage to an item and sent (along with the item) a $1 / 3$ refund of the selling price. So 
the "description" element of rule one, though open to abuse, is much more critical at a virtual auction than at a physical auction.

In the second element of this rule in oral auctions, the auctioneer often finds an opening bid in the Dutch style (decreasing asked amounts until someone bids), only then ascending toward a selling price in the English fashion (Kuiper 1992). This is one technique that on-line auctions have yet to imitate-eBay uses a minimum bid, set by the seller, and there is no "opening bid search." As a consequence, items often fail to receive even one bid on-line. In an offline auction, lacking a reserve price, typically everything sells. The Dutch auction descent to an opening bid might get down to several things grouped together for a dollar, but it all sells. At eBay, finding an opening bid is simplified: the seller sets it.

Bid calling, so directly associated with the auctioneer and the chant of traditional English auctions, also has undergone revision on eBay. A high bidder is acknowledged not with a nod or a declaration of the new high bid, but with the listing of the high bidder's username next to "High bid" and the current bid (one increment above the next-highest bid) next to the "Currently" label on the auction listing page. To keep track of the bidding, particularly in the final moments of an eBay auction, an observer cannot hear the interchange, but can follow it by clicking on "reload" every few seconds until the auction ends.

Although auctions on eBay last up to ten days and a potential bidder knows exactly when the auction will end, it is difficult to always know exactly where a person stands in the bidding in the interim (as one would in a traditional English auction). To keep bidders informed, eBay informs a bidder immediately after a bid whether or not that bid is currently the high bid. If it is, the screen message says, "Thank you for your bid. You are the current high bidder!" After 
restating the current bid and the bidder's maximum proxy bid, eBay adds, "Although you are the current high bidder, this does not guarantee that you will win this item. Someone may outbid you in the last few minutes, so check back often or place a proxy bid" ("eBay Confirming Bid," emphasis theirs, 2000). To keep bidders even better apprised of the bid calling, e-mail messages are sent to confirm bids and to alert bidders to being outbid. An "Outbid Notice" warns, "Heads up! Another eBay user has outbid you on the following item!" It offers the current bid amount and the auction closing time, and urges, "you can stay in the running and place another bid. Just visit (item site)" ("eBay Outbid Notice” 2000). Although participants in a virtual auction are not always present in real time, eBay mimics the offline auctioneer's involvement by using e-mail encouraging bidders to bid again. This is not unlike the offline auctioneer goading bidders into bidding wars against each other, often with witticisms or with compliments about the bidder's judgment or the item's quality.

Another significant function of "bid calling" in an in-person English auction is the determination of a bidding increment. In calling for the next higher bid, the auctioneer determines this increment; for less expensive items it may be in single dollars, and for more expensive items or items receiving many bids, it may be in hundreds or even thousands of dollars. As bidding winds down and bidders drop out, an auctioneer might decrease the increment asked for between bids, a procedure known as splitting the bid (Cassady 1967; Smith 1989). Bidding might progress, for instance, as $100,150,200,250,260,270$. By reducing the increment between bids as they become harder to obtain, the auctioneer maximizes the selling price of each item. On eBay, the bidding increment also changes-as the price escalates, the bidding increment increases as well, from $\$ 1.00$ to $\$ 2.50$ and so on. Once increased, however, 
the bidding increment on eBay is never split-the "virtual auctioneer" asks for a minimum new bid in the amount of the current bid plus bidding increment and will accept nothing less, even if it is higher than the existing bid. If, for instance, an item were selling for $\$ 110.00$, a bid of $\$ 111.00$ would not be accepted-the bidding increment at this level is $\$ 2.50$ and the new minimum bid would be $\$ 112.50$. This state of affairs leaves eBay less flexible than a live auctioneer who can choose whether or not to ask for (or accept) a split bid. Bidders at live auctions, as the bidding escalates, often attempt through a gesture to cut the increment in half in hopes of reducing the final price. The auctioneer is often willing to accommodate this change if he or she believes it will result in happier participants or a slightly higher final bid. Although eBay provides less flexibility than the live auctioneer, however, it still determines the bid increment and asks for the next bid, just as the auctioneer does with a chant.

On eBay, a seller can reduce risk by indicating a reserve price on an item for sale. This affects bidding by absolving both bidder and seller from commitment until the reserve is met. Ordinarily, an auction requires two interested bidders in order for bidding to advance. But in eBay's reserve system, a maximum bid equal to or greater than the reserve price results in the current bid being automatically listed as the reserve price:

The reserve price is the lowest price a seller is willing to sell an item for. This amount is generally higher than the minimum bid. In order to win the auction, a bidder must meet or exceed the reserve price and have the highest bid. If a bidder's maximum bid meets or exceeds the reserve, the bid will be automatically raised to meet the reserve . ("Reserve price auction" 2000) 
At a live auction, reserves are often used as well. As a substitute for an announced reserve, however, an auctioneer might also pretend to recognize nonexistent bids until the seller's minimum price is met: this practice is known alternatively as bidding for the vendor, running or trotting (Cassady 1967, 105, 166), lift-lining (Graham and Marshall 1987), bidding to the chandelier, or taking bids off the wall (Smith 1989, 150). In auctions where the practice is recognized as acceptable, auctioneers sometimes accept phantom bids against an actual bidder in order to boost the selling price to the seller's preset reserve (Smith 1989, 156). Whether or not this practice is acceptable depends upon the legitimacy it has within that auction community: does the community consider the practice useful and responsible (Epstein 1972)? For sellers, it is certainly useful in raising the bid to an acceptable level-bidders (who might also sometimes sell) might be willing to accept the practice as responsible as long as reserves are reasonable and phantom bids do not continue beyond those reserves.

Auctioneers end auctions in a variety of ways after only one bidder remains in the auction. This announcement varies in form-it might consist of the word sold, it might involve restating the final price and the buyer, it might include the dropping of a gavel, or it might invoke any other number of local variations.

Though imitating these two basic elements (when to end and how to end an auction), the "sale" at eBay differs significantly from traditional auctions. First, as a time-interval auction, an eBay auction can end while several bidders are still interested in bidding. In theory, of course, the proxy bidding system ensures that all bidders can bid their maximum bid. In reality, because auctions serve to determine a price for items where value is in question, bidders might not know 
their maximum bids until they see how much other bidders value the item. Consequently, continued bidding might persuade a bidder that an item is worth more than the bidder initially thought. If time runs out, however, the auction is over regardless of continued interest.

Some eBay users try to take advantage of this situation through the practice of sniping. With rare exceptions at live auctions ${ }^{\mathrm{iii}}$, bidding continues until all bidders but one have bowed out. There is always one last chance to bid. From an economic standpoint in such auctions, "losers tell the truth" (Hendricks and Paarsch 1995, 413). That is, when a bidder drops out, that bidder reveals his or her highest valuation for an object. And if bidding continues, that bidder reserves the right to reenter the auction until the pronouncement of sale, at which time the losing bidder's true maximum is revealed. Remorse for not bidding again may well set in after the gavel falls, but each bidder has equal opportunity to participate, all the way until the end. Even if bidders have predetermined a maximum bid for an item, they can continue to revise that upward as others' bids affect their valuation (see Smith 1989).

On eBay, however, lurks the potential that losers lie. A person who is outbid in the auction's closing seconds has no opportunity to reconsider a true maximum bid-the auction is irrevocably finished. The lack of the "one last chance" that a live auction affords has led to the pejorative term sniping on eBay, to describe bidding behavior whereby a potential bidder lurks at auction until the final seconds, entering a true maximum bid and (if it is high bid) preempting further bids by participants who might be influenced to raise theirs. This system of eBay's is in some ways more predictable than a traditional auction (bidders know PRECISELY when the auction will end), but it also allows less opportunity for bidders to change their minds. Sniping is also not a new practice--Samuel Pepys recorded in his diary a procedure in Great Britain's 
candle auctions of the seventeenth century that foretells the practice of sniping on eBay in the twenty-first: "The bidder may, in fact, be able through careful study to anticipate the final flicker of the candle, and hence prevail in the competition by topping the previous high bid at the very last moment" (Pepys, qtd. in Cassady 1967, 76).

Obviously there is no auctioneer to cry, "Sold!" at eBay and no gavel with which to pound, but eBay attempts to imitate the ending rituals of in-person auctions. As soon as an auction ends, a notice is e-mailed to buyer and seller stating, "Dear [seller] and [buyer], Congratulations-this auction successfully ended" ("eBay end of auction" 2000). It then reminds buyer and seller of the item and its description, informs them of the final price and ending time of the auction, lists the total number of bids, and identifies buyer and seller by both username and e-mail address so that the two can make contact and exchange payment for item. As the auctioneer's "Going once, going twice-sold!", these messages serve to both bring closure to the sale and affirm the buyer and seller for their participation in the auction. Just like an auctioneer, eBay wants its users to be happy, repeat customers.

Kuiper's (1992) optional "epilogue" might explain to bidders where to pay for their items and when and where items will be available for pickup. EBay provides the same in its "End of Auction" notice. It offers a list titled, "Here's what to do next" that explains that method by which buyer and seller will contact each other, complete the transaction, and leave feedback, with helpful links to each. The addition of feedback actually extends this epilogue much longer in time than at a typical auction, where payment and removal of the item mark the end of the interaction. Buyers on eBay will likely not leave feedback for a seller until the item is paid for and received, sometimes several weeks after the close of the auction. This extends the virtual 
auction in actual time and also maintains a lengthier association between buyer and seller than is typical of in-person English auctions.

Rule 2: auction sale -> (introduction) + auction (Kuiper 1992, 282)

Kuiper (1992) uses the term auction sale to denote the entire event; at eBay, one item equals one auction. One modification to his rule, then, adds an $(s)$ to the end of his second rule, allowing for a single auction sale to comprise multiple auctions. Amended, rule two would be thus:

Rule 2: auction sale $->$ (introduction) + auction(s)

Rule three is an expansion of the optional introduction of rule two, in which elements might or might not be included, and in no particular order.

Rule 3: introduction $\rightarrow[$ (welcome to buyers $)+($ description of sale $)+$ $($ conditions of sale $)+($ order of sale $)+($ peripheral practicalities $) \ldots]$ (where square brackets denote relatively free order choices) [Kuiper 1992, 282]

While both virtual and actual auctions include both a welcome and a description, eBay emphasizes the former and traditional auctions the latter. At a traditional auction, there is 
usually some unifying trait for the entire auction—perhaps it is the estate of the late Estelle Howe, a monthly consignment auction, or Keeneland's thoroughbred yearling sale. In contrast, eBay's unifying feature is a lack of unity. Almost anything and everything is sold on eBay by hundreds of thousands of sellers. So broad is eBay's set of items that there are entire categories in such oddities as nodders and flue covers (Whitman 1999).

EBay, however, emphasizes the welcome more than traditional auctions do, where a welcome might be so brief and informal that it is easy to miss. EBay's homepage is a virtual welcome to all potential bidders and sellers. Under "Welcome New Users," there are links to common questions such as, "How do I bid?" and "How do I sell?" And through a "New to eBay?" link, users are greeted with this message:

Welcome! It's the world's first, biggest and best person-to-person on-line trading community. eBay is your place to find the stuff you want, to sell the stuff you have and to make a few friends while you're at it! (“New to eBay?” 2000)

The conversational tone of this welcome matches the oral greeting of the auctioneer and tries to create the same readiness for trading.

Conditions of sale at a live auction can be prominently posted in an auction catalog or at the auction site, or they might be explained by an auctioneer before the auction begins. Two common conditions of sale (though there are variations) provide that purchased items be fully paid for before they are removed and that an auctioneer can refuse the bids of irresponsible bidders (Cassady 1967). These common conditions at actual auctions mirror conditions eBay 
allows at its virtual auctions. Sellers typically wait for checks to clear before shipping items, and sellers may reserve the right to ignore bids by users with lots of negative feedback so that sellers take on the policing function of auctioneers.

Order of sale is not a significant issue on eBay: auctions end three, five, seven, or ten days from when they are posted, depending on the sellers' preferences. Order is relatively random and dependent on when different people in different time zones list different items for bids. At a traditional auction, in contrast, auctioneers often lay out a schedule for the auction in advance. Sometimes there is no doubt of order: a catalog has listed items to be sold in the order they will come up. Other times, there seems to be no order at all—the auctioneer moves through items for sale seemingly at random. Physical space can constrain order; at a car or tobacco auction, bidders might proceed down the rows, with the auctioneer selling each piece as the procession moves along. At other times, certain categories of items might be auctioned together at a preordained time in the sale. The auctioneer might say, "We'll start with some smalls, we'll sell the guns at noon, and we'll get to the furniture at 1:30." This schedule is a courtesy to bidders who are only interested in certain items, but there might still be flexibility to sell requested pieces. EBay's schedule, on the other hand, is both arbitrary (in terms of starting time) and fixed (in terms of ending time).

In this rule, "peripheral practicalities" might include where restrooms, food, and drink might be found during the sale, information about emergency exits, or other mundane but necessary matters. At eBay, with a less linear progression of events, "peripheral practicalities" are always available on the site: information about safe trading at eBay, eBay logo merchandise for sale, and other nonessential ingredients of the eBay auction community can be accessed any 
time, not only at the beginning of an auction.

So in spite of its lack of an auctioneer and an oral chant, eBay manages to follow the rules of English auctions. Still, differences surrounding timed auctions, fixed bidding intervals, feedback, and "sniping" lend eBay a different character. Other differences remain as well.

One feature of the in-person auction with auctioneer is that a particularly frenzied single auction, or an impressive price for a high quality item, can some times draw applause (Smith 1989). This author has witnessed spontaneous applause at live auctions many times. EBay, unfortunately, cannot imitate this concentrated give-and-take between auctioneer and the auction community, in part because of the fact that a single auction can last up to ten days.

EBay also has no exact analog to the auctioneer's chant, even though it fulfills the basics of auction rule number one. The functions of the chant, however, are served in other ways. Filler words in a chant provide, among other things, a chance for bidders to consider their bids by quickly analyzing everything they know about the item up for bid. Sometimes this leaves bidders scrambling for cell phones and reference books. EBay bidders, however, do not need a chant to serve this delaying purpose because they have time. While the auction is still going on (for as long as ten days), they have the opportunity to research items on the Internet or through reference books, perhaps even making inquiries of authorities. As Hendricks and Paarsch (1995, 408-9) have observed, "uninformed potential buyers are less likely to participate than the informed potential buyer, but when they do participate, they bid high rather than low." EBay's timed system of up to ten days allows uninformed buyers to inform themselves, thus increasing the likelihood that they will bid, but also counteracting their tendency at live auction to overbid in ignorance. 
Conclusion

In many ways, eBay is not so different from traditional English auctions. Most significantly, however, it lacks an auctioneer. Without an auctioneer, it would seem to lack the accountability and control that auctioneers exercise during in-person auctions. EBay has compensated for this lack, however by imitating the auctioneer's orality in site construction, in security measures, and in e-mail bulletins. As a result, new users continue to flock to eBay and other on- line auctions.

EBay's successful imitation of orality might create other on-line opportunities in areas that seem too oral to translate to a computer screen. Teaching and medical consultation are just two areas in which the orality of in-person interactions seems essential to the entire process. For education and medical websites to gain the adherents that eBay has, they will have to mimic the oral nature of the interactions they attempt to replace or at least supplement.

Virtual auctions' impact on live, located auctions remains to be seen. One auctioneer, however, has expressed optimism, comparing the new on-line/offline auction split to the tension created among movie theater owners with the creation of videocassette recorders. Gordon (1999) suggested that on- line auctions give traditional auctioneers opportunities to expand their current businesses us ing emerging technologies while garnering benefits of increased attention to auctions in general. In the end, eBay might even familiarize enough people with auctions that the live auction itself becomes less intimidating, and the auctioneer an ally, not a sharp-tongued enemy. 


\section{Notes}

i The term choice is used when several items are up for bid at once; the high bidder can choose one or more items from the group, each priced at the closing bid. By the piece, two times the money means that two related or identical items are up for sale at the same time-each bid is for the price of one item, but when the bidding is over, the bidder will take both items at twice the final bid.

ii In theory, eBay is also quite similar to a Vickrey auction (Smith 1989), which is a sealed bid auction in which the highest bidder wins the item at the second-highest bid. The reality is that many bidders do not take advantage of the proxy bidding, instead watching the bidding and upping their bids only by small increments. Additionally, the high bidder pays a price one increment above the second-highest bid rather than paying only the amount of the second-highest bid. This resembles a Vickrey, however, because of its sealed-bid character and because one increment above the second-highest bid could still be significantly lower than the proxy bid submitted by the highest bidder.

iii Smith (1989) describes sales at the New England Fish Exchange where bidding on each kind of fish was closed after five minutes. 


\section{Glossary}

feedback $n$ Written comment evaluating performance left for an individual eBay user by another user

neg $v$ Leave a negative feedback comment for an eBay user

proxy bid $n$ Maximum bid left with the auctioneer and used only as much as necessary to maintain the proxy bidder's leading position in the auction

snipe $v$ Bid on a timed auction in the closing seconds, preventing other bidders from entering new bids 


\section{References}

Anders, George. 1999a. Amazon, EBay Announce Acquisitions, Alliances for On-line-Auction Businesses. Wall Street Journal, 13 April, B6.

---. 1999b. Investors in EBay Inc. Worry About Costs. Wall Street Journal, 27 October, B6. Aw-confirm@ebay.com [on-line]. 2000, January 20. EBay end of auction. Message to author. Aw-confirm@ebay.com [on-line]. 2000, January 28. EBay outbid notice. Message to author.

Bierce, Ambrose. 1911; reprint, New York: Dover Publications, 1958. The devil's dictionary.

Cassady, Ralph., Jr. 1967. Auctions and auctioneering. Berkeley: Univ. of California Press.

DeVany, Arthur. 1987. "Institutions for Stochastic Markets.” Journal of Institutional and Theoretical Economics 143: 91-103.

"EBay Announces Fourth Quarter and Year End" [on-line]. 2001, January 18 [cited 22 February 2001]. Available from: http://www.shareholder.com/ebay/news/20010118-31808.htm. EBay confirming bid [on-line]. 2000, January 31 [cited 31 January 2000]. Available from: http://cgi.ebay.com/aw-dgi/eBayISAPI.dll

“EBay Inc. Releases Third Quarter 2000 Financial Results” [on-line]. 2000, October 19 [cited 15

December 2000]. Available from: http://www.shareholder.com/ebay/news/2000101926289.htm. 
Epstein, Edwin M. 1972. "The Historical Enigma of Corporate Legitimacy.” California Law Review 60: 1701-1717.

Gordon, B. 1999, May 13 [cited 1 September 1999]. “The Auction Business Is Changing!” Auction Marketing Institute [on-line]. Available from:

http://www.auctionmarketing.org.

Graham, Daniel A., and Marshall, Robert C. 1987. "Collusive Bidder Behavior at Single-Object Second-Price and English Auctions. Journal of Political Economy 95: 1217-1239.

Grant, L. 1999. “Going, Going, Gone.com.” USA Today, 17 May, B1, B2.

Hendricks, K., and Paarsch, H. J. 1995. “A Survey of Recent Empirical Work Concerning Auctions. Canadian Journal of Economics 28: 403-426.

"How to sell" [on-line]. 2000, January 31 [cited 31 January 2000]. Available from: http://pages.ebay.com/help/sellerguide/selling_how.html.

Kagel, John H., and Levin, Dan. 1993. “Independent Private Value Auctions: Bidder Behaviour in First-, Second- and Third-Price Auctions with Varying Numbers of Bidders." The Economic Journal 103: 868-879.

Kuiper, Koenraad. 1992. “The Oral Tradition in Auction Speech.” American Speech 67: 279289.

---. 1996. Smooth Talkers: The Linguistic Performance of Auctioneers and Sportscasters. Mahwah, NJ: Lawrence Erlbaum Associates. 
Lucking-Reiley, David. 2000. Auctions on the Internet: What's being auctioned, and how? Journal of Industrial Economics, 48: 227-52. Available from http://www.vanderbilt.edu/econ/reiley/papers/InternetAuctions.pdf.

“New to eBay?" [on- line]. 2000, February 1 [cited 1 February 2000]. Available from: http://pages.ebay.com/help/basics/n-index.html.

“A New Web Site Offers a Way to Auction Inventions On-line.” 1999. Wall Street Journal, 30 November, B2.

"Proxy bidding" [on-line]. 2000, January 31 [cited 31 January 2000]. Available from: http://pages.ebay.com/help/basics/g_proxy_bidding.html.

"Reserve price auction" [on- line]. 2000, January 31 [cited 31 January 2000]. Available from: http://pages.ebay.com/help/basics/g-reserve-auction.html.

Rundle, R. L. 1999. "Pharmaceuticals to Be Auctioned on Web." Wall Street Journal, 1 December, B6.

Smith, Charles W. 1989. Auctions: The Social Construction of Value. Berkeley: Univ. of California Press.

“Surfing for Stogies.” 1998. Business News New Jersey, 12 October, 11.

"Web Surfers Spend 23 Percent More Time Online than Last Year, According to Nielson/Netratings." 2000. Nielson//Netratings: Defining Standard in Internet Research (Web site). 15 Nov. (accessed 15 Dec. 2000). Available from 
http://209.249.142.22/press_releases/PDF/pr_001115.pdf.

Whitman, Margaret. 1999. Letter to the eBay community. EBay: The World's Online Marketplace (Web site). 30 Dec. (accessed 11 Jan. 2000). Available from h ttp://pages.ebay.com/community/letter.html. 